\title{
Exploration of Elements Affecting the Main Properties of Screw Steel
}

\author{
Siwen Li1, Qiaozhi Sang1, Shuqi Wang², Dianxuan Gong ${ }^{3 *}$ \\ ${ }^{1}$ Yisheng College, North China University of Science and Technology, Tangshan, China \\ ${ }^{2}$ College of Architectural Engiring, North China University of Science and Technology, Tangshan, China \\ ${ }^{3}$ College of Science, North China University of Science and Technology, Tangshan, China \\ Email: ^dxgong@ncst.edu.cn
}

How to cite this paper: Li, S.W., Sang, Q.Z., Wang, S.Q. and Gong, D.X. (2018) Exploration of Elements Affecting the Main Properties of Screw Steel. Open Journal of Applied Sciences, 8, 184-188. https://doi.org/10.4236/ojapps.2018.85015

Received: April 30, 2018

Accepted: May 28, 2018

Published: May 31, 2018

Copyright (c) 2018 by authors and Scientific Research Publishing Inc. This work is licensed under the Creative Commons Attribution International License (CC BY 4.0).

http://creativecommons.org/licenses/by/4.0/

\section{(c) (i) Open Access}

\begin{abstract}
In order to obtain the main and secondary factors affecting the properties of the screw steel and its correlation, this text constructed a TOPSIS (Technique for order performance by similarity to ideal solution) evaluation system based on entropy weight. First of all, three properties indexes of deformed steel bar are selected: the yield strength, tensile strength and elongation at break after breaking. Secondly, we defined a comprehensive index $\mathrm{C}$ which is for measuring the property of thread steel by using TOPSIS method, and then the correlation degree of various chemical elements and comprehensive index $\mathrm{C}$ were analyzed. According to the principle that the bigger of coefficient correlation, the greater impact, to draw a conclusion: the main elements that affect the properties of deformed steel bar are $\mathrm{C}, \mathrm{Ceq}, \mathrm{Si}$ and $\mathrm{Cr}$, the secondary factors are $\mathrm{Mn}, \mathrm{Mo}, \mathrm{ALT}, \mathrm{Ni}, \mathrm{Cu}, \mathrm{Cr}, \mathrm{S}, \mathrm{P}$ and $\mathrm{V}$. Finally, the correlation between various elements was studied by means of correlation analysis, where there was a significant positive correlation between $\mathrm{Cu}$ and $\mathrm{Cr}$.
\end{abstract}

\section{Keywords}

Screw Steel, Properties, Grey Prediction, Correlation Analysis

\section{Introduction}

Hot-rolled ribbed bar is commonly known as deformed steel bar, it's mainly used for skeleton of reinforced concrete component and it requires certain mechanical strength, bending and deformation properties, fabrication weldability. The chemical composition [1] in steel is the basic element that influences the final structure property of hot rolled steel. As for this article, firstly, yield strength, tensile strength and percentage elongation after fracture are measured by means 
of TOPSIS comprehensive evaluation method. And then, based on the correlation degree analysis, the influence of various chemical elements is investigated.

\section{Determine Main and Secondary Influence Factors}

The TOPSIS comprehensive evaluation method based on entropy weight is used to determine the primary and secondary influence factors and secondary factors that affect the screw steel.

\subsection{Data Processing}

The yield strength, tensile strength and percentage elongation after fracture are the indexes where higher numbers would indicate improved properties. That is, in general, the higher the value of the properties of the screw thread steel, the better the properties. In order to avoid the error caused by the data which are too large or too small, it is necessary to narrow the difference between the various indicators. According to the information given by the title, $t$ is not difficult to find that the elongation at break is $1 / 10$ of the other two indicators. Therefore, it is necessary to deal with the percentage elongation after fracture.

The unit of the selected indicators of the unit is bound to have an impact on the evaluation results. Therefore, it is necessary to carry out non dimensional treatment of properties index. The standard deviation formula is:

$$
\hat{X}_{i j}=\frac{X_{i j}-\bar{X}_{i}}{\sqrt{\sum_{j=1}^{N}\left(X_{i j}-\bar{X}_{i}\right)^{2}}}
$$

\subsection{Determine the Weight of the Index}

Considering different indicators have different impact on the overall properties of deformed steel bar of different sizes. We assign different weights to each index. In this paper, the entropy weight method [2] is used to calculate the specific gravity of the index value of the $j$ th items under the $i$ th indexes:

$$
P_{i j}=\frac{r_{i j}}{\sum_{i=2}^{m} r_{i j}}
$$

The $j$ th indicators of entropy $e_{j}$ :

$$
e_{j}=-k \sum_{i=1}^{m} p_{i j} \cdot \ln p_{i j}, k=\frac{1}{\ln m}
$$

\subsection{The Solution of Closeness Degree}

We use the entropy weight method to determine the weight of each index. For vector $w_{i}$, Weighted normalization of the decision making matrix is needed. That is $V=\left(v_{i j}\right)_{m \times n}$ By each row of the matrix and the corresponding weights are multiplied [3]: 


$$
V=\left[\begin{array}{cccc}
v_{11} & v_{12} & \cdots & v_{1 n} \\
v_{21} & v_{22} & \cdots & v_{2 n} \\
\vdots & \vdots & \ddots & \vdots \\
v_{m 1} & v_{m 2} & \cdots & v_{m n}
\end{array}\right]=\left[\begin{array}{cccc}
r_{11} \cdot w_{1} & r_{12} \cdot w_{1} & \cdots & r_{1 n} \cdot w_{1} \\
r_{21} \cdot w_{2} & r_{22} \cdot w_{2} & \cdots & r_{2 n} \cdot w_{2} \\
\vdots & \vdots & \ddots & \vdots \\
r_{m 1} \cdot w_{m} & r_{m 2} \cdot w_{m} & \cdots & r_{m n} \cdot w_{m}
\end{array}\right]
$$

Through the formula (4) to obtain the decision matrix, then calculate the positive and negative ideal solution of the normalized weighted target according to the matrix:

$$
\begin{gathered}
V^{+}=\left\{\max _{1 \leq i \leq m} v_{i j} \mid i=1,2, \cdots, m\right\}=\left\{v_{1}^{+}, v_{2}^{+}, \cdots, v_{m}^{+}\right\} \\
V^{-}=\left\{\min _{1 \leq i \leq m} v_{i j} \mid i=1,2, \cdots, m\right\}=\left\{v_{1}^{-}, v_{2}^{-}, \cdots, v_{m}^{-}\right\}
\end{gathered}
$$

The distance between each sample evaluation vector to the positive ideal solution and the distance from the negative ideal solution are calculated respectively:

$$
\begin{aligned}
& D_{j}^{+}=\sqrt{\sum_{i=1}^{m}\left(v_{i j}-v_{i}^{+}\right)^{2}} \\
& D_{j}^{-}=\sqrt{\sum_{i=1}^{m}\left(v_{i j}-v_{i}^{-}\right)^{2}}
\end{aligned}
$$

$v_{i j}$ is the weighted normalized value of the $j$ th sample of item $i$ th. $v_{i}^{+}$is the most preferred value of the $i$ th index in the sample evaluation. $v_{i}^{-}$isthe least preference value of the $i$ th index in the sample evaluation.

The distance between positive and negative ideal solutions of each evaluation vector calculated by the formula (7-8). The formula for calculating the degree of closeness is as follows:

$$
C_{j}=\frac{D^{-}}{D^{-}+D^{+}},(1 \leq j \leq n)
$$

The closeness degree determined by the TOPSIS method is a number between 0 and 1. Its value is bigger, the properties of deformed steel bar is better. We randomly selected a part of the specification 1 of deformed steel bar, the data is processed to get the close degree of deformed steel bar as follows in Table 1.

\section{Grey Relational Grade Analysis}

Grey correlation analysis method is a kind of multivariate statistical analysis method, it uses the sample data of each factor as the basis to describe the strength, size and order of the factors by using the gray correlation degree. If the sample

Table 1. Closeness degree.

\begin{tabular}{ccccccc}
\hline Sample number & 1 & 2 & 3 & 4 & 5 & 6 \\
\hline Closeness degree & 0.4 & 0.5 & 0.48 & 0.44 & 0.42 & 0.44 \\
Sample number & 7 & 8 & 9 & 10 & 11 & 12 \\
Closeness degree & 0.5 & 0.46 & 0.52 & 0.48 & 0.48 & 0.43 \\
Sample number & 13 & 14 & 15 & 16 & 17 & 18 \\
Closeness degree & 0.48 & 0.46 & 0.49 & 0.51 & 0.5 & 0.45 \\
\hline
\end{tabular}


data shows the Changing trend of two factors is basically consistent, then the correlation between them is large; otherwise, the correlation degree is small.

The problem requires us to analyze the main factors that affect the properties of deformed steel bar and the secondary factors. Then there is a certain relationship between these chemical elements and the properties of deformed steel bar. The grey incidence analysis can describe the relationship, so the correlation degree analysis method is suitable to solve the problem. Its expression is [4]:

$$
\xi_{i}(k)=\frac{\min _{s} \min _{t}\left|x_{0}(t)-x_{s}(t)\right|+\rho \max _{s} \max _{t}\left|x_{0}(t)-x_{s}(t)\right|}{\left|x_{0}(k)-x_{i}(k)\right|+\rho \max _{s} \max _{t}\left|x_{0}(t)-x_{s}(t)\right|}
$$

In the above formula: $x_{0}(t)$ is properties index of deformed steel bar. $x_{i}(t)$ is a kind of chemical elements. $\min _{s} \min _{t}\left|x_{0}(t)-x_{s}(t)\right|$ is the minimum value of two kinds of chemical elements. $\max _{s} \max _{t}\left|x_{0}(t)-x_{s}(t)\right|$ is the maximum value of two kinds of chemical elements.

Select a chemical element $i$ as a reference matrix, $j$ properties indexes of deformed steel bar are used as comparison matrix, it can describe the relationship between the chemical element $i$ and the $j$ properties index of deformed steel bar. First, take the specification 1 of deformed steel bar as an example, and to conduct grey relational grade analysis. Then use MATLAB programming to calculate $\xi_{i}(k)$ between each index. Because each index has 7124 samples, it is difficult to directly use the results to show the correlation degree of each index, we decided to adopt the method of calculating the average value. Its expression is:

$$
r_{i}=\frac{1}{N} \sum_{i=1}^{N} \xi_{i}(k)
$$

By calculating the correlation coefficient between various chemical elements and specification 1 of deformed steel bar. Results are shown in Table 2.

Table 2. Specification 1 relevance coefficient table.

\begin{tabular}{cc}
\hline Element & Relational coefficient \\
\hline C & 0.842690315 \\
MN & 0.385319304 \\
S & 0.681769835 \\
P & 0.682625118 \\
Si & 0.786744008 \\
Ceq & 0.852312833 \\
V & 0.685073796 \\
Cr & 0.779288711 \\
Ni & 0.672630768 \\
CU & 0.674601003 \\
MO & 0.665564375 \\
ALT & 0.669861883 \\
\hline
\end{tabular}


In the same way, we can get the correlation coefficient of various kinds of chemical elements on the properties of deformed steel bar of specification 2 .

Combined with two specifications of deformed steel bar, the main factors and secondary factors that influence the properties of deformed steel bar are analyzed according to the correlation coefficient of two tables. The correlation coefficient of Ceq, C , Cr and Si on specification 1 of deformed steel bar are $0.852,0.843$, 0.779 and 0.787 respectively. $0.845,0.848,0.782$ and 0.776 are on specification 2.They are all more than 0.7 , so it shows that these four kinds of chemical elements are the main factors that influence the properties of deformed steel bar. And $\mathrm{Mn}, \mathrm{Mo}, \mathrm{ALT}, \mathrm{Ni}, \mathrm{Cu}, \mathrm{Cr}, \mathrm{S}, \mathrm{P}$ and $\mathrm{V}$ are the secondary factors that affect the properties of deformed steel bar. We find this result is consistent with the actual situation by consulting relevant information [5].

\section{Conclusions}

In the current standard, the upper and lower limits of the main elements $\mathrm{C}, \mathrm{Si}$, and $\mathrm{Mn}$ are clearly defined; $\mathrm{P}$ and $\mathrm{S}$ are harmful elements, and the upper limit is limited. Other elements are residual trace elements, and the control requirements for V, Ti, B, Ca, and Sn have not yet been clearly defined.

According to our conclusion that $\mathrm{Ceq}, \mathrm{C}, \mathrm{Cr}$ and $\mathrm{Si}$ are the main factors that affecting the properties of screw steel while $\mathrm{Mn}, \mathrm{Mo}, \mathrm{ALT}, \mathrm{Ni}, \mathrm{Cu}, \mathrm{Cr}, \mathrm{S}, \mathrm{P}$, and $\mathrm{Si}$ are secondary ones. It has been recognized that $\mathrm{Cu}, \mathrm{Cr}, \mathrm{Ni}, \mathrm{Mo}$, etc. do have an effect on the performance of the steel, so their content is expected to be standardized further.

\section{Acknowledgements}

This project is supported by National Natural Foundation of China (11301120, 11601151), National Natural Foundation of Hebei Province (A2015209189) and young talents support project of Hebei Province.

\section{References}

[1] Lima-Junior, F.R. and Carpinetti, L.C.R. (2016) Combining SCOR ${ }^{\circledast}$ Model and Fuzzy TOPSIS for Supplier Evaluation and Management. International Journal of Production Economics, 174, 128-141. https://doi.org/10.1016/j.ijpe.2016.01.023

[2] Hatami-Marbini, A. and Kangi, F. (2016) An Extension of Fuzzy TOPSIS for a Group Decision Making with an Application to Tehran Stock Exchange. Applied Soft Computing, 52, 1084-1097. https://doi.org/10.1016/j.asoc.2016.09.021

[3] Zhang, K., Ye, W. and Zhao, L.P. (2012) The Absolute Degree of Grey Incidence for Grey Sequence Base on Standard Grey Interval Number Operation. Kybernetes, 41, 11. https://doi.org/10.1108/03684921211257784

[4] (1983) Effect and Effect of Main Elements on Properties of Steel. Metal Recycling, 04, 45-48.

[5] Zhang, X.L., Li, X.F. and Li, J. (2014) Correlation Analysis and Properties Evaluation of Fusion Image Quality Evaluation Index. Acta Automatic Sinica, 02, 306-315. 